\title{
The Summer Parental Investment Gap? Socioeconomic Gaps in the Seasonality of Parental Expenditures and Time with School-Age Children*
}

\author{
Orestes P. Hastings \\ Colorado State University \\ pat.hastings@colostate.edu
}

\author{
Joe LaBriola \\ University of California, Berkeley \\ joelabriola@berkeley.edu
}

October 8, 2021

\begin{abstract}
Scholars have theorized how private parental investments of money and time in children may respond differentially to the loss of the public provision of schooling during the summer, based on parental socioeconomic status (SES). Importantly, the widening of SES gaps in parental investments of money and time in children during the summer could generate SES gaps in children's learning during the summer. We investigate the seasonality of SES gaps in parental investments of both money and time using the 1996-2018 Consumer Expenditure Survey and 2003-2019 American Time Use Survey. We find SES gaps in parental investments of both money and time during the summer and SES gaps in expenditures are larger in the summer than during non-summer months. We find little evidence that these gaps have grown substantially over time, but we do find these gaps are larger for younger school-age children than for older school-age children. This research provides new evidence regarding the link between public and parental investments in children, addresses a key mechanism underlying the debate about the summer learning gap, and provides new evidence on how parents may target investments in children towards the ages when they are most consequential.
\end{abstract}

Keywords: inequality, time use, expenditures, family, parenting

${ }^{*}$ The authors are grateful for helpful comments from Shawna Bendeck, Daniel Schneider, and participants at the 2020 American Sociological Association annual meeting. 


\section{Introduction}

As spring fades into summer, most schools in the United States close their doors and let students out for a summer break. Scholars and educators have taken great interest in how parents structure children's activities and spend with children during these summer months, and whether parental investments of money and time during the summer are stratified by parental socioeconomic status (hereafter, SES). In the short run, these SES-based gaps could exacerbate school achievement gaps (Alexander, Entwisle, and Olson 2007; Burkam et al. 2004; Downey et al. 2004; Entwisle and Alexander 1995, but see Hippel and Hamrock 2019; von Hippel et al. 2018), and in the long run they could reinforce existing inequalities in children's life chances that stem in part from their position in the "birth lottery" (Blau and Duncan 1967; Corak 2013; Chetty et al. 2014, 2017; Mitnik, Bryant and Grusky 2018).

SES inequalities in children's outcomes are caused in part by inequalities in school experiences (Aikens and Barbarin 2008; Crosnoe 2009; Murnane and Reardon 2018; Gamoran 1992; Oakes 2005; Auwarter and Aruguete 2008; Calarco 2018), yet these effects may pale in comparison to the effects of inequalities in children's out-of-school experiences (Duncan and Murnane 2011; Kalil, Ryan, and Corey 2012; Schneider, Hastings, and LaBriola 2018). Entwisle, Alexander, and Olson (2001) used the analogy of school as a "faucet" which provides somewhat (though not entirely) equal resources into the lives of children of all SES backgrounds. When this stream of resources is turned off during the summer, then children can only access parental resources, which are distributed less equally.

We first elaborate on these mechanisms, explaining how both public and parental investments shape children's outcomes and how these investments are stratified by parental SES. We then summarize research on the timing of parental investments, particularly focusing on what we do and do not know about how summer parental investments vary by parental SES. We develop five hypotheses about the seasonality of SES gaps in parental investments to answer a number of questions: (1) Do summer parental investment gaps exist? (2) Do they widen during summer months? (3) Has this gap grown over time? (4) Has this gap has grown more rapidly than the gap in parental investments during the school year? And, (5) does the magnitude of this gap differ by the age of children?

We answer these questions in the context of both parental investments of money and time using the 1996-2018 Consumer Expenditure Survey and the 2003-2019 American Time Use Survey. While studies frequently address either parental investments of money and time, we jointly investigate both types of investments. This is important because, on the one hand, money spent on enrichment activities or childcare could potentially crowd the amount of time that parents spend with their children, which would attenuate the effect of SES gaps of parental investments of money on child outcomes. But, on the other hand, SES gaps of both time and money could increase in the summer, which would implicate wider SES inequalities in child outcomes.

We find evidence of gaps by SES - measured in terms of both parental education and income - in parental investments of both time and money during the summer. These gaps for expenditures on children are larger in the summer than during non-summer months. While the gaps for maternal or paternal time in child care are not wider in the summer than during the school year, the net result (considering both types of investments) is greater SES gaps in parental investments during summer. We do not find evidence that these gaps have grown substantially over time, suggesting increases in intensive parenting practices characteristic of high-SES parents are not especially concentrated during the summer. We

find that higher-income parents spend significantly more on younger children ages 6-11 than 
older children ages 12-17. The same income gap for time use is not statistically significant, but in the same direction, and more educated fathers spend significantly more time with younger children than older children. The net result is that SES gaps in summer parental investments are larger among parents of younger children than among parents of older children.

This research contributes to three important strands of the literature on parental investments and children's outcomes. First, it provides new evidence regarding the link between public and parental investments in children. Second, it addresses one of the key mechanisms underlying the debate about the summer learning gap. Finally, third, it provides new evidence regarding how parents may target investments in children towards the ages when they are most consequential.

\section{Background and Hypotheses}

\subsection{Public and Parental Investments as a Sources of Inequality}

Despite the American dream that socioeconomic attainment does not depend on background, there is a relatively high degree of intergenerational persistence of income (Chetty et al. 2014; Mitnik, Bryant, and Weber 2019), education (Bloome, Dyer, and Zhou 2018), occupation (Hout 2018), and wealth (Pfeffer and Killewald 2018) in the United States. Scholars studying the mechanisms underlying this intergenerational transfer of SES have focused on the roles of both public and private investments in children.

The most central public investment in children that directly shapes their outcomes is schooling. While children from all backgrounds are promised free education through high school, children from higher-SES families are more likely to attend better resourced and higher-performing public schools (Aikens and Barbarin 2008; Crosnoe 2009) or attend private school (Murnane and Reardon 2018), resulting in significant advantages for children from higher-SES families. Even within the same school, children of high-SES families may still receive better teaching and more advantages over children from lower-SES families (Gamoran 1992; Oakes 2005; Auwarter and Aruguete 2008; Calarco 2020).

However, other research suggests these school-based inequalities may be smaller and less significant than inequalities in children's family environments. In particular, parenting practices associated with the "concerted cultivation" of cultural and human capital in children (Lareau 2002, 2011) are positively associated with greater cognitive ability and academic achievement among children (e.g., Bodovski and Farkas 2008; Cheadle 2008; Greeman, Bodovski, and Reed 2011; Hsin and Felfe 2014; Price and Kalil 2018). Scholars have focused on two broad forms of intensive parenting: (1) financial investments parents make to pay for children's childcare and schooling, enrollment in supplementary and extracurricular activities, and the purchasing of items and materials necessary for the those in and out-ofschool activities; and (2) the extent, content, and quality of the time parents spend with their children.

Though recent research finds that parents from all socioeconomic backgrounds generally aspire to engage in this intensive parenting (Ishizuka 2019), higher-SES families are more likely to do so, plausibly because they have more resources to invest in their children (Bennett et al. 2012; Cheadle and Amato 2011; Hao and Yeung 2015). The result is that there are substantial gaps by parental education and income in parental investments of both time and money. For example, Schneider, Hastings, and LaBriola (2018) show that households in the top income quartile spend over three times as much on financial investments in their children 
as households in the bottom income quartile (see also, Kornrich and Furstenberg 2013; Kornrich 2016). Likewise, research shows that more educated parents spend significantly more time in childcare than less educated parents (Gauthier, Smeeding and Furstenberg, 2004; Sayer, Gauthier, and Furstenberg 2004; Kalil, Ryan, and Corey 2012; Altintas 2016; LaBriola and Schneider 2021), although the gap between more and less educated mothers has closed significantly recent years (Prickett and Augustine 2021) While income is perhaps logically the strongest predictor of parental investments of money in children, Cheadle and Amato (2011) find that parental education is in fact the largest correlate of parenting practices associated with the concerted cultivation of children's abilities.

\subsection{The Origins and Timing of Children's Achievement Gaps}

Out-of-school SES inequalities can widen during three phases of children's development (Davies, Aurini, and Milne 2019). First, there is strong evidence that SES gaps in children's cognitive ability begin to originate before children even begin kindergarten (Heckman 2006, 2008; von Hippel, Workman, and Downey 2018; Reardon and Portilla 2011). Research has documented increasingly higher expectations for children's academic skills prior to entering kindergarten, for which high-SES parents may be better positioned to prepare their children (Bassok, Latham, and Rorem 2016)

Second, SES gaps can emerge during the school year but outside of school hours. Student learning not only occurs in formal classroom settings, but also through family environments and extracurricular activities. Higher-SES parents are more likely to supplement their children's schooling with a "shadow education" of formal and informal extracurricular activities (Park et al. 2016).

Third - and central to this paper - SES gaps may arise when school is out of session during the summer. In fact, until very recently, a preponderance of research comparing the rate of growth of children's test scores over school and non-school months suggested that it is over the summer, not during the school year, in which SES gaps in cognitive ability grew most (e.g., Alexander, Entwisle, and Olson 2007; Burkam et al. 2004; Downey et al. 2004; Entwisle and Alexander 1995). However, new research has found issues with score alignment between different tests and changes in test forms that have overstated what is commonly termed the "summer learning gap" (von Hippel and Hamrock 2019; von Hippel et al. 2018). Alongside this new research, it is also important to actually understand what parents and children do in summer, as the summer learning gap literature suggests this is the central mechanism that may (or may not) drive SES inequalities in children's cognitive abilities.

Furthermore, beyond cognitive skill development and academic achievement, much of the time children spend with parents and the activities they participate in may help children develop cultural capital, which research shows has also powerful effects on hiring opportunities and workplace success (e.g., Rivera 2012; Turco 2010). Thus, it is important examine how a broad array of parental investments during the summer may be patterned by parental SES.

\subsection{The "Other Faucet": Seasonality in Parental Investments}

In contrast to the careful and ongoing research on seasonal patterns to children's achievement gaps, little research has examined whether there is seasonality in gaps in parental investments of time and money. This is important given that parental investments of time and money are the mechanisms predicted to create seasonal patterns in children's achievement gaps. 
Entwisle, Alexander and Olson (2001) use the analogy of school providing a "faucet" of resources that is turned off during the summer. When the faucet is turned on during the school year, all students gain in ability (somewhat) equally. However, when the faucet of school resources is turned off during the summer, children's resources for learning and development primarily come from parental investment, which is distributed far less equally than school resources. These investments can take the form of payments for various enrichment activities (e.g., day or overnight camps, supplemental education, sports programs, music lessons) and/or spending more time talking and playing with children, reading to children, and coordinating children's activities.

The faucet analogy suggests parents maintain similar levels of their parental investment during the summer as they do during the school year. However, this claim has received little empirical attention, and there is good reason to expect SES gaps in parental investments in children to instead widen during the summer. Research has found a direct link between public investments and SES inequalities in parental investments in children. Cascio and Schanzenback (2013) found that the introduction of universal preschool programs in Georgia and Oklahoma during the 1990s led higher-SES parents to reduce their childcare expenses. More recently, using longitudinal data with both state-level public investment data and household parental expenditures, Jackson and Schneider (2021) found greater public spending is associated with narrower class gaps in parental investments. One of the mechanisms was that public spending on public education was linked to decreases in spending among high-SES households. But, researchers have not examined this link by comparing summer months - when children do not receive public resources from schooling - to non-summer months - where they do.

Both qualitative and quantitative research find a stark SES gap in children's summertime activities. In ethnographic work, Chin and Phillips (2004) observed that children in highSES families experienced very full summer schedules that included vacations, day camps, educational activities, music lessons, sports, and other enrichment activities and outings. On the other hand, children in low-SES families had less opportunity for these activities, even though their parents also appeared to value these experiences and attempted to provide them as possible. Instead, these parents were constrained by a lack of affordable options for their children and less-accommodating work schedules. These findings are corroborated by statistical analyses of the Early Childhood Longitudinal Study (ECLS-K), which show that higher-SES children are more likely to go to trips to historical sites and museums, attend camp, and receive tutoring than are low-SES children (Meyer, Princiotta, and Lanahan 2004; Redford, Burns, and Hall 2018).

This research on the SES gap in children's summertime activities suggests, but does not show, that there are also large SES gaps in parental investments of money and time during the summer. Moreover, this work generally does not assess whether these SES gaps in parental investments are larger during the summer that during the school year. One notable exception is research by Gershenson (2013) that examined seasonality in parental investments of time (but not money) and found evidence that SES gaps in time spent managing children's activities widened by a moderate amount during the summer.

Based on this literature, we derive the following hypotheses. First, we examine whether and by how much higher-SES families invest more money and time in their children during the summer than lower-SES families (that is, whether higher-SES families "keep the faucet on" during the summer). While prior scholarship supports this hypothesis, and thus support for it would not come as a surprise, a test of it also provides a measure of the size of the gap between high and low SES parents. We then examine whether these gaps in parental 
investments are larger in the summer than during the school year, which might reflect higher-SES parents increasing their parental investments (i.e., "turning up the faucet") to compensate for school being out.

Hypothesis 1: SES gaps in parental investments exist during the summer.

Hypothesis 2: SES gaps in parental investments are greater in the summer than during the school year.

\subsection{Changes over Time in the Seasonality of Parental Investments}

Research has documented how, compared to several decades prior, parents on average spend more money on and more engaged time in childcare with their children (Schneider, Hastings, and LaBriola 2018). The increase in parental investments of money has largely been driven by higher-SES parents (Kornrich and Furstenberg 2013; Kornrich 2016). Schneider et al. (2018) documented how rising income inequality is responsible for widening class gaps in parental investments of money in children, finding evidence that rising inequality has both afforded higher-income families more money to spend on their children and additionally has influenced higher-SES parents to spend an increasing share of their income on investment goods for children.

The research on widening SES gaps in time use is more mixed. One study of young children (but not including school-age children) observed widening SES gaps between 1988 and 2012 in time-intensive parenting behaviors that are associated with greater school readinessincluding reading to and telling stories to children and teaching children basic reading and math skills (Kalil et al. 2016). However, another study examining kindergarteners in 1998 and 2010 found that there were significant but narrowing SES gaps in parental engagement in learning activities both inside and out of the home (Bassok et al 2016). More generally, gaps in parental childcare time by parental income and education widened through the 2000s (Ramey and Ramey 2010; Altintas 2016), but appear to have stalled and even narrowed since (Cha and Park 2020; Prickett and Augustine 2021).

Nevertheless, given widening SES gaps in parental investments of money in children, SES gaps in total parental investments in children have likely widened. We examine whether there has been a parallel widening summer SES gaps in parental investments in children

over time. Moreover, widening SES gaps in parental investments in children over time could reflect increased investments by high-SES parents during the summer to compensate for school being out. We thus examine whether SES gaps in parental investments of children are disproportionately widening during the summer.

Hypothesis 3: SES summer gaps in parental investments have widened over the past several decades.

Hypothesis 4: SES summer gaps in parental investments have widened more than SES non-summer gaps in parental investments over the past several decades.

\subsection{Differences in parental investments by child age}

Finally, there may also be variation in the seasonality of SES gaps in parental investments by age of children. One highly-cited model of child development suggests returns on investment in children's abilities, whether via direct investment in their human capital (Heckman 2006) or via moving to more advantaged neighborhoods (Chetty, Hendren, and Katz 2016), are 
largest when children are younger. If higher-SES parents target their increased investments in children during the summer at the ages when they are most consequential (e.g., Kalil et al. 2012), then we may see wider SES summer gaps in parental investments towards younger school-aged children.

On the other hand, much of the narrative around concerted cultivation has focused on higher-SES parents investing in activities like extra tutoring, SAT prep courses, and resume fillers that will help their children get into an elite college (e.g., Cooper 2014), and these investment activities are more likely to occur when children are in middle and high school. This leads to two plausible competing hypotheses that we can examine:

Hypothesis 5A: SES summer gaps in parental investments are larger for younger school-age children than older school-age children.

Hypothesis 5B: SES summer gaps in parental investments are larger for older school-age children than younger school-age children.

\section{The Current Paper}

This paper advances current research in several key ways. First, despite the growth in parental spending on activities designed for children's enrichment both during and outside the school year, we are not aware of any other work examining the seasonality of SES gaps in parental investments of money. Previous studies that document differences by SES in children's summer activities have relied on binary measures from the ECLS-K of whether or not certain pre-selected activities occurred at all (e.g, Meyer, Princiotta, and Lanahan 2004; Redford, Burns, and Hall 2018). Our analysis of the amount of spending on these activities is advantageous in that it captures all spending within the enrichment categories regardless of the specific activity, provides a rough proxy for the quality of those activities (to the extent that quality is associated with cost), and is available across many years.

Similarly, although - as reviewed in this paper - there has been a great deal of research on the parental time use, there is little research that explores its seasonality, with the exception of Gershenson's (2013) analysis noted above ${ }^{1}$ Our research advances further on Gershenson (2013) in two substantial ways. First, we separately examine time investments of mothers and fathers. Mothers perform substantially more childcare than fathers (Bianchi 2000, Altintas 2016, Cha and Park 2020), and SES gaps in childcare time are wider among mothers than among fathers (Schneider, Hastings, and LaBriola 2018, Cha and Park 2020). Further, ethnographic research suggests that mothers are primarily responsible for coordinating children's enrichment activities during the summer (Lareau 2011). As such, the seasonality of SES gaps may differ between mothers and fathers. Second, we more than double the observations of previous research examining SES gaps in time use over the summer (Gershenson 2013) by extending the analysis through 2018. This also allows us to see if SES summer gaps in parental childcare have widened over this time frame, consistent with rising anxiety among high-SES parents about their children's outcomes (e.g., Cooper 2014).

\footnotetext{
${ }^{1}$ Some of this may be due to the fact the best available time use survey of children - the Child Development Study supplement of the Panel Study of Income Dynamics - only samples children during the school year. Gershenson (2013) also analyzes the some dimensions of children's time use without their parents using the Activity Pattern Survey of California Children. The focus of our paper is specifically on parental investments of time (and money), so this is beyond the scope of our analysis.
} 
More broadly, we examine each ceteris paribus hypothesis separately for outcomes of parental investments of expenditures on children's enrichment and of time through childcare. Both types of investment in children's lives are understood to contribute to children's achievement and long-term outcomes in adulthood, yet there are also potential trade-offs between the two. Money spent on enrichment activities or childcare could potentially reduce the amount of time that parents spend with their children. However, it is also possible that SES gaps of both time and money increase in the summer, which would widen inequalities. As such, any broad conclusions about the seasonality in SES gaps in parental investments in children should take into account both parental investments of time and money.

\section{Data}

We test these hypotheses about the seasonality of parental investments using publicly available microdata from two large, nationally-representative, long-running surveys: the Consumer Expenditure Survey (CEX) and the American Time Use Survey (ATUS). The analysis of each dataset focuses on households with school-age children (ages 6-17) who are likely to be impacted by the seasonality of schooling. Below, we describe the each dataset in detail, with descriptive statistics provided in the Appendix.

\subsection{Consumer Expenditure Survey}

We use the 1996-2018 CEX to conduct the first empirical analysis of SES gaps in spending on children's enrichment activities by season. We focus on the CEX Interview surveys, which capture relevant measures of parental investments and are collected quarterly from each household for four consecutive quarters. Crucially, although each survey collects a full quarter (3 months) of expenditures, each expenditure is associated with the particular month that the expense occurred. It is plausible that, in some cases, the month in which the investment expense occurred is not the same month as when the child actually experiences that investment. This could occur if, for example, parents pay for larger expenses like school tuition or summer camp in advance, or conversely if parents are able to smooth out large one-time payments over several months. To the extent that parents pay for summer investments in children outside the summer, or vice versa, this will downwardly bias the coefficients in our models reflecting seasonal differences in expenditures on child investments. Thus, class gaps in the investments purchased by parents that children actually experience during the summer maybe actually be wider than our models report.

Given our focus on school-age children, we exclude families with children under 6 because we only know each family's total expenditures in a given category and not to which child the expenditure was directed. Altogether, our expenditure analysis is based on observations from 39,207 households in 274,445 household-months.

\subsubsection{Measures of Parental Investments of Money}

We examine expenditures related to enrichment activities (e.g, fees for recreational lessons, instruction, and other extracurriculars), childcare (e.g., costs for babysitting, nannies, day care centers, and nursery schools), and schooling (e.g., student room and board; summer school, books, supplies, and equipment for school; tuition; and any other primary and secondary school-related expenses). Following existing work, we use the combined measure of these expenditures and divide by the number children in the household to generate per-child 
expenditure measure (Hastings and Schneider 2021; Schneider, Hastings, and LaBriola 2018; Kornrich and Furstenberg 2013; Kornrich 2016). Focus on the combined measure captures the breadth of expenditures that may each give small accumulated advantages to some children over others, and it captures shifts in spending between investment categories that are likely to occur between summer and non-summer months (i.e., schooling to enrichment activities). Our dollar amounts are adjusted to 2018 real dollars using the CPI-U-RS.

Given the high tuition of private school, costs associated with paying for private school may also substantially impact the results. For robustness, we assess the sensitivity of the results to models that exclude families whose investments on schooling are in the top $10 \%$ of households, since about $10 \%$ of primary school students attend a private school (Murnane and Reardon 2018).

We also considered the possibility that increases summer investments of money might merely reflect increases need for paid childcare during the summer. For robustness, we also ran and report on separate models for childcare and for non-childcare expenditures.

\subsubsection{CEX Independent Variables}

We operationalize SES in terms of both household income and parental education. For income, we divide the sample into three groups: the bottom $25 \%$, middle $50 \%$, and top $25 \%$. We found substantively similar results using codings of income quartiles and quintiles, but for clarity and parsimony we prefer to report the results from the 3-category model. For education, we separate households based on the whether the most educated parent in the household has obtained a Bachelors degree. A binary "Summer" variable indicates whether an expense took place in summer (June and July) or non-summer (September though April) months. We exclude May and August because these months typically include both in-school and out-of-school periods.

Our control variables are the age of the oldest parent, race of each parent (with flags for single-parent households), work hours of each parent, whether or not the children's grandparents live in the home, the number of children aged 6-11, and the number of children aged 12-17.

\subsection{American Time Use Survey}

We use data from the 2003-2019 American Time Use Survey (ATUS) to analyze SES gaps in parental investments of time by season. These nationally-representative data, hosted online by IPUMS (Hofferth et al. 2020), contain information from a 24-hour time diary of a chosen adult in a household that recently completed their participation in the Current Population Survey (CPS), alongside information on respondent SES, family structure, and demographics. As with the expenditure analysis, we focus on parental respondents who are living with at least one own child under age 18 and who do not live with a child under age 6. After dropping respondents with missing values for household income, our final ATUS analysis sample contains 16,687 mothers and 11,534 fathers.

\subsubsection{Measures of Parental Investments with of Time with Children}

The main dependent variable is the total amount of time a parental diarist reports performing primary childcare for household children as their primary activity. This includes time in basic care (care of infants, general care of older children, and medical care of children), playing, teaching (supervising children, helping them with homework, and reading to or 
talking with children), and management (including coordination of extracurricular activities and travel related to childcare). This definition of primary childcare is consistent with measures of parental investments of time used in previous research (e.g., Bianchi et al. 2006; Kalil et al. 2012; Altintas 2016; Schneider, Hastings, and LaBriola 2018).

\subsubsection{ATUS Independent Variables}

As with the expenditure analysis, we operationalize SES in terms of both household income and parental education in the same way as for the expenditure analysis 2 As in our CEX analyses, we define the binary dependent variable "Summer" as above and control for the partnership status (married or cohabitating versus other), age, and race/ethnicity of the parental diarist, along with household size and the age of the youngest household child. Rather than controlling for parental employment status, as in the CEX analyses, we instead control for time spent in paid work during the diary day, which is likely to crowd out time spent performing childcare. In addition, because time use is spent differently during weekdays than during weekends (Hill et al. 2018), we also control for whether the time diary was completed on a weekday or weekend.

\section{$5 \quad$ Plan of Analysis}

We estimate linear regression models to examine the seasonality of parental investments in children. In the equations below, we bold the key coefficients to test the relevant hypotheses.

First, we test Hypothesis 1 with a model that uses only observations from the summer months. Formally, we write this model as:

$$
\text { Parental Investments }=\beta_{0}+\boldsymbol{\beta}_{\mathbf{1}} \boldsymbol{S E} \boldsymbol{S}+\beta_{2} \text { Controls }+\mu_{\text {year }}
$$

where $S E S$ is our categorical variables for SES, Controls is a vector of individual and household level controls, and $\mu_{\text {year }}$ are year fixed effects, included to net out overall time trends in parental investments. $\beta_{1}$ is a vector of coefficients representing the estimate for each SES category, relative to the baseline categories of the middle income quartiles for income and not having a Bachelor's degree for education. We include both income and education SES measures in the same model, but the results considering them separately are similar and included in the Appendix.

Second, to test Hypothesis 2, we analyze all observations from summer and non-summer months, and include a dichotomous variable for summer and an interaction between summer and SES:

$$
\begin{aligned}
\text { Parental Investments } & =\beta_{0}+\beta_{1} \text { Summer }+\beta_{2} S E S+\boldsymbol{\beta}_{\mathbf{3}} \boldsymbol{S E S} \times \mathbf{S u m m e r} \\
& +\beta_{4} \text { Controls }+\mu_{\text {year }}
\end{aligned}
$$

The estimate of $\beta_{3}$ informs Hypothesis 2 by capturing the seasonal differences in parental investments by SES. In the expenditure analysis, we have multiple months of data for each household, so we can also employ household-level fixed effects $\left(\mu_{\text {household }}\right)$ that control for the

\footnotetext{
${ }^{2}$ The household income of ATUS respondents who filled out their final CPS survey before October 2003 was coded under a scheme that does not accurately allow us to separate middle- and high-income households. As such, we drop these households from our analysis.
} 
main effect of other time-invariant household characteristics. While the fixed effect absorbs the main effect of SES, the interaction term may reintroduce time-invariant confounders associated with both SES and parental financial investments. We account for this possibility by including interactions between SES and each control variable (time invariant or not).

The models in Equations 1 and 2 capture average differences by SES in the pooled data. Next, we test Hypotheses 3 and 4 by examining whether those differences have grown over time during the analysis periods. We next estimate the following model using only summer observations:

$$
\text { Parental Investments }=\beta_{0}+\beta_{1} \text { Year }+\beta_{2} S E S+\boldsymbol{\beta}_{\mathbf{3}} \boldsymbol{S E} \boldsymbol{S} \times \boldsymbol{Y} \text { ear }+\beta_{4} \text { Controls }
$$

where the estimates of $\beta_{3}$ show how much the gap widened over time, all else being equal (testing Hypothesis 3). Although Equation 3 shows a linear growth model, we also find substantively similar results with more complex growth trajectories (e.g., higher-order polynomials) and we present non-parametric plots of these trends over time.

We then test if the SES summer gaps in parental investments have widened more than SES non-summer gaps in parental investments over the past several decades. For this test we use all observations and add to the model coefficients for Summer, the interactions of Summer $\times Y$ ear and Summer $\times S E S$, and a triple interaction of $S E S \times Y e a r \times S u m m e r$. Evidence of a widening gap more in the summer than the school year would be supported by a significant and positive coefficient for the triple interaction.

$$
\begin{aligned}
\text { Parental Investments } & =\beta_{0}+\beta_{1} \text { Year }+\beta_{2} S E S+\beta_{3} \text { Summer }+\beta_{4} S E S \times \text { Year } \\
& +\beta_{5} S E S \times \text { Summer }+\beta_{6} \text { Year } \times \text { Summer } \\
& +\boldsymbol{\beta}_{\mathbf{7}} \boldsymbol{S E S} \times \boldsymbol{Y} \text { ear } \times \text { Summer }+\beta_{8} \text { Controls }
\end{aligned}
$$

Finally, we test Hypotheses 5A and 5B, which asks if the seasonality of SES gaps in parental investment in children differs between households with younger and older schoolaged children. Here, we focus on families for whom all children are either aged 6-11 or are aged 12-17, since we cannot determine whether investments are directed towards older or younger school-aged children for families with children in both age categories. We re-estimate the models corresponding to Equations 1 and 2, now additionally including an interaction between SES and a variable indicating whether all household children are aged 6-11 or are aged 12-17.

$$
\begin{aligned}
\text { Parental Investments } & =\beta_{0}+\beta_{1} \text { Childs }^{\prime} \text { Age }+\beta_{2} S E S+\boldsymbol{\beta}_{\mathbf{3}} \boldsymbol{S E S} \times \boldsymbol{C h i l d s}^{\prime} \boldsymbol{A g e}(\boldsymbol{s}) \\
& +\beta_{4} \text { Controls }+\mu_{\text {year }}
\end{aligned}
$$

All of our models include sampling weights. The time-use models use survey replicate weights that account for sampling variance, and the expenditure models include standard errors clustered by households. 


\section{Results}

\subsection{Summer Gap}

Table 1 shows the analysis testing Hypotheses 1 and 2. Models 1, 4, and 6 estimate the differences in parental investments during summer months by SES, while Models 2, 3, 5, and 7 estimate the seasonality of these differences.

As predicted by Hypothesis 1, the models show SES gaps during the summer. In Model 1, families where at least one parent has a BA spend - on average and all else being equalabout $\$ 102$ per month more (in 2018 dollars) during the summer than a family without a BA. Similarly, families in the highest income quartile spend $\$ 106$ more monthly than those in the middle quartiles and $\$ 118$ more than those in the bottom quartile.

Model 2 examines whether these SES gaps in parental expenditures are larger in the summer than school during the school year, as predicted by Hypothesis 2. "Non-summer" is the reference category for season, the SES coefficients in Model 2 reflect the non-summer SES gaps. These coefficients indicate that SES gaps in parental investments exist during the school year as well as during the summer. To examine the seasonality of this gap, we focus on the interaction terms. Model 3 also examines Hypothesis 2, but also include household fixed-effects ${ }^{3}$ In both models, we find larger increases in the summer (vs. school year) for highly educated (vs. less educated) families and for families in the top income quartile (vs. the middle and bottom quartiles).

We illustrate these gaps by calculating the predicted parental investments of money by season and SES using the coefficients from Model 2 (setting all other covariates to their mean) and plotting these values and their confidence intervals in the first column of Figure 1. The figure highlights the large overall differences by SES, as well as the increases in investments during the summer months for the most-educated and highest-income households.

We next look at whether SES gaps in parental investments of time are wider during the summer, and whether the size of SES gaps in parental investments of time vary between summer and the school year. We look at maternal time use (Models 4 and 5 of Table 1 and Column 2 of Figure 1) separately from paternal time use, given substantial differences in the amount of time that mothers and fathers perform in child care.

Model 4 reveals wide education-based gaps in maternal investments of time in children during the summer. All else equal, mothers with at least a Bachelor's degree spend 19 minutes more of daily childcare time than do other mothers of school-aged children, even after accounting for household income. However, income-based gaps in maternal investments of time in children during the summer are not statistically significant. Model 5 shows that mothers spend about 25 fewer minutes doing primary childcare during the summer than during the school year. The coefficients on the interaction terms suggest that SES gaps in maternal investments of time in children do not change significantly during summer as compared to the school year, though the coefficient on the interaction between having a Bachelor's degree and summer is no quite significantly different from 0 at conventional levels of significance $(\mathrm{p}=.08)$.

\footnotetext{
${ }^{3}$ The sample size is slightly smaller in the fixed effects model because the small number of households that changed their education level or income quartile are excluded, so that the interaction term can be interpreted as only the effect of a change in the season.
} 
Table 1: Regression Models of Parental Investments

\begin{tabular}{|c|c|c|c|c|c|c|c|}
\hline & \multicolumn{3}{|c|}{ Expenditures } & \multicolumn{2}{|c|}{ Maternal Time } & \multicolumn{2}{|c|}{ Paternal Time } \\
\hline & $\begin{array}{c}(1) \\
\text { Summer }\end{array}$ & $\begin{array}{c}(2) \\
\text { Full Year }\end{array}$ & $\begin{array}{c}(3) \\
\text { Full Year, FE }\end{array}$ & $\begin{array}{c}(4) \\
\text { Summer }\end{array}$ & $\begin{array}{c}(5) \\
\text { Full Year }\end{array}$ & $\begin{array}{c}(6) \\
\text { Summer }\end{array}$ & $\begin{array}{c}(7) \\
\text { Full Year }\end{array}$ \\
\hline BA or higher & $\begin{array}{c}101.5^{* * *} \\
(7.25)\end{array}$ & $\begin{array}{l}73.5^{* * *} \\
(3.55)\end{array}$ & & $\begin{array}{l}18.9^{* * *} \\
(4.48)\end{array}$ & $\begin{array}{l}9.61^{* * *} \\
(1.98)\end{array}$ & $\begin{array}{l}10.1^{* *} \\
(3.80)\end{array}$ & $\begin{array}{l}12.3^{* * *} \\
(1.87)\end{array}$ \\
\hline Bottom income quartile & $\begin{array}{r}-12.1 \\
(6.39)\end{array}$ & $\begin{array}{c}-12.8^{* * *} \\
(3.73)\end{array}$ & & $\begin{array}{c}-2.26 \\
(4.74)\end{array}$ & $\begin{array}{c}-1.59 \\
(2.64)\end{array}$ & $\begin{array}{c}-1.49 \\
(4.24)\end{array}$ & $\begin{array}{r}-3.83 \\
(2.29)\end{array}$ \\
\hline Top income quartile & $\begin{array}{c}105.7^{* * *} \\
(8.97)\end{array}$ & $\begin{array}{l}86.6^{* * *} \\
(4.25)\end{array}$ & & $\begin{array}{c}0.32 \\
(5.20)\end{array}$ & $\begin{array}{c}5.57 \\
(2.95)\end{array}$ & $\begin{array}{c}-1.94 \\
(3.94)\end{array}$ & $\begin{array}{c}3.13 \\
(2.48)\end{array}$ \\
\hline Summer & & $\begin{array}{c}-11.4^{* * *} \\
(2.74)\end{array}$ & $\begin{array}{c}61.1 \\
(56.8)\end{array}$ & & $\begin{array}{c}-25.3^{* * *} \\
(3.07)\end{array}$ & & $\begin{array}{c}-10.1^{* * *} \\
(3.06)\end{array}$ \\
\hline BA or higher $\times$ Summer & & $\begin{array}{l}29.7^{* * *} \\
(7.60)\end{array}$ & $\begin{array}{l}28.1^{* * *} \\
(8.26)\end{array}$ & & $\begin{array}{c}7.78 \\
(4.51)\end{array}$ & & $\begin{array}{c}-2.44 \\
(4.23)\end{array}$ \\
\hline Bottom income quartile $\times$ Summer & & $\begin{array}{c}3.19 \\
(5.39)\end{array}$ & $\begin{array}{c}-1.91 \\
(7.56)\end{array}$ & & $\begin{array}{c}-1.15 \\
(4.75)\end{array}$ & & $\begin{array}{c}2.59 \\
(4.60)\end{array}$ \\
\hline Top income quartile $\times$ Summer & & $\begin{array}{l}18.8^{*} \\
(8.53)\end{array}$ & $\begin{array}{l}22.9^{*} \\
(9.24)\end{array}$ & & $\begin{array}{c}-6.56 \\
(6.01)\end{array}$ & & $\begin{array}{r}-5.66 \\
(4.49)\end{array}$ \\
\hline Observations & 54888 & 274445 & 266129 & 3290 & 16687 & 2216 & 11534 \\
\hline
\end{tabular}

Standard errors in parentheses

${ }^{*} p<.05,{ }^{* *} p<.01,{ }^{* * *} p<.001$

Source: Consumer Expenditure Survey 1996-2018, American Time Use Survey 2003-2019.

Controls and year fixed effects included in all models. Model 3 with household fixed effects also includes interactions between summer and each control variable. 

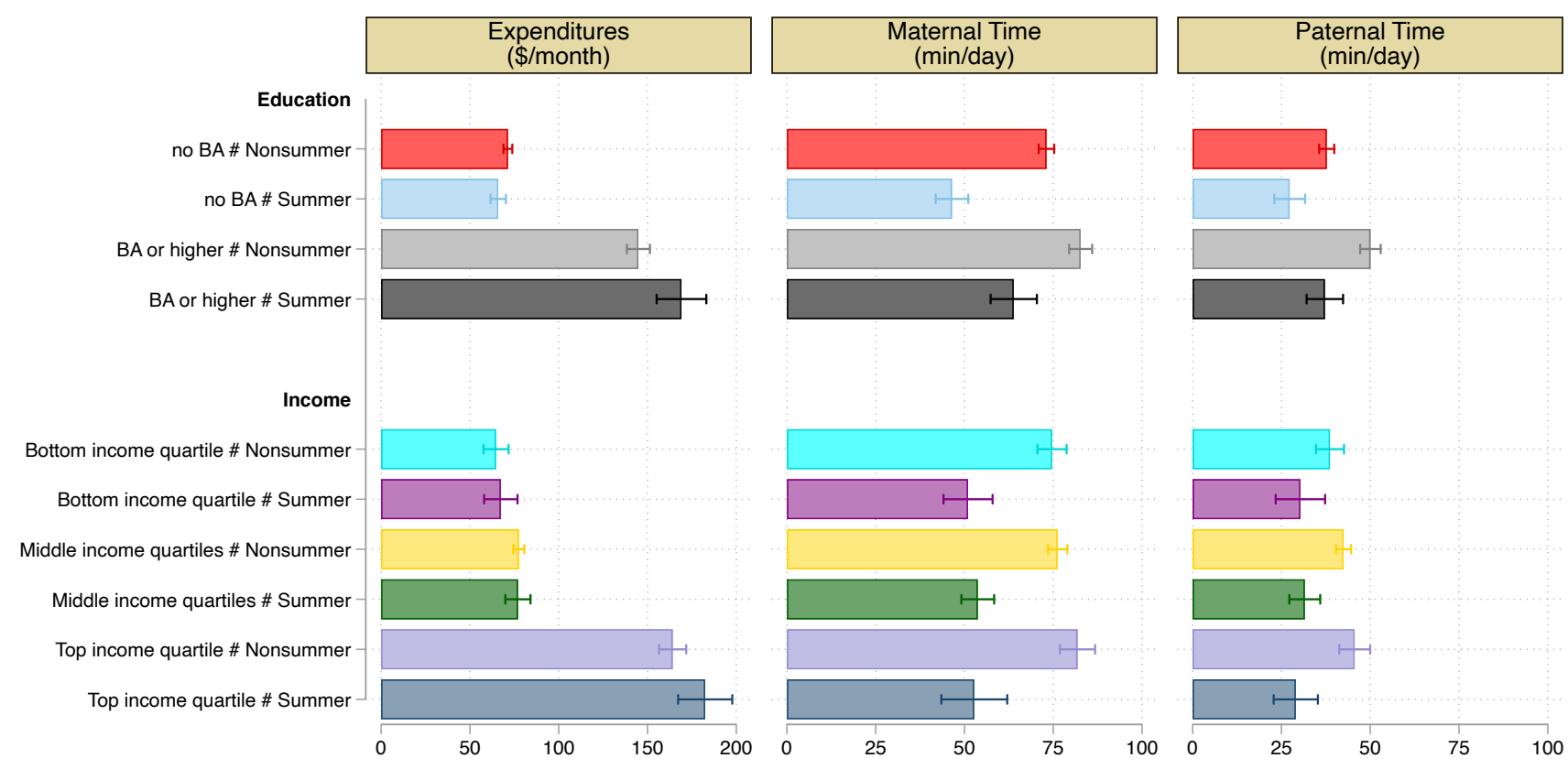

Figure 1: Predicted Parental Investments

Turning to paternal investments of time in children, we see a similar story. During the summer, fathers with at least a Bachelor's degree perform about 10 more minutes of childcare time per day than do fathers without Bachelor's degrees, net of observable characteristics (Model 6). However, we find no evidence of income-based gaps in paternal childcare time during the summer. We also see no evidence that SES gaps in paternal childcare time widen during the summer (Model 7).

The time use results are visualized in Columns 2 and 3 of Figure 1 , highlighting several broad features: first, consistent with previous research, mothers spend far more time doing child care than fathers. Second, both mothers and fathers spend less time doing child care in the summer. Third, SES gaps in childcare time exist by parental education for both mothers and fathers, but these are similarly sized across seasons.

In sum, these results support Hypothesis 1 that there are significant SES gaps in parental investments in children during the summer. The results provide partial support to Hypothesis 2; while SES gaps in parental investments of money widen during the summer, there is no evidence of seasonality in SES gaps in parental investments of time. However, given that the time use gaps also do not decrease during the summer, the net result is when considering money and time use together, SES gaps in parental investments widen during the summer, at the same time that equalizing public investments in children in the form of schooling are no longer present.

\subsection{Change over Time}

Our next set of analyses examine whether these gaps have changed over time. First, Figure 2 presents non-parametric lowess plots of the average parental investments in summer and non-summer months over time period of the analyses, for each education and income subgroup (unconditional of other factors). Looking at the top panel of the first column, 
summer expenditures appear to have grown somewhat for the families where at least one parent has a Bachelor's degree, and decreased slightly among other families, leading to an overall widening gap in summer expenditures. Similarly, looking at the bottom panel of the first column, we see an increase in summer expenditures for the top income quartile, and a decrease for the bottom income quartile, also leading to a widening gap. However, within SES groups, summer and non-summer parental expenditures of money on children generally appear to move together over time.

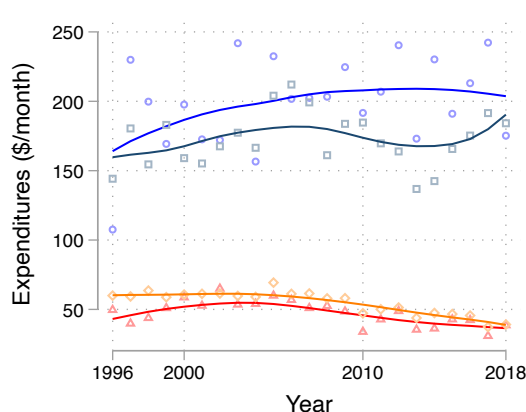

- $B A+$, summer

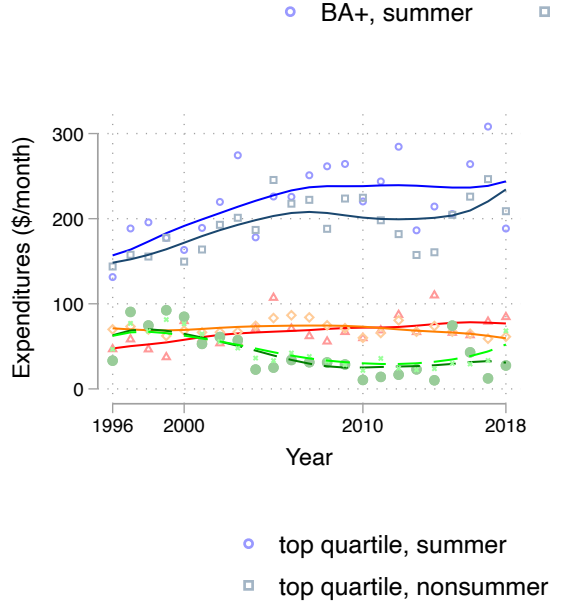

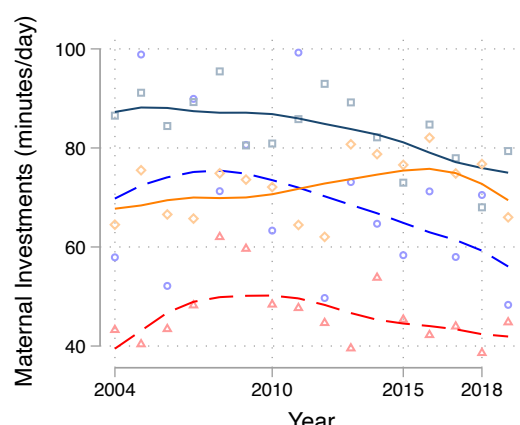

BA+, nonsummer

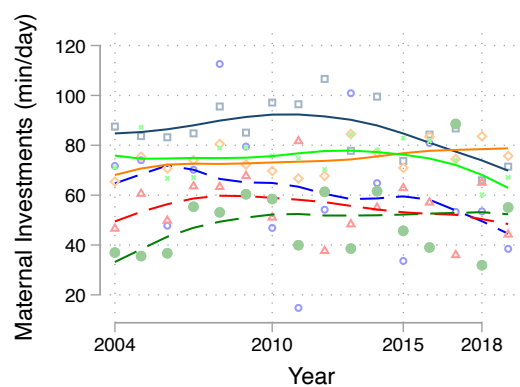

$\Delta$ middle quartiles, summer middle quartiles, nonsummer

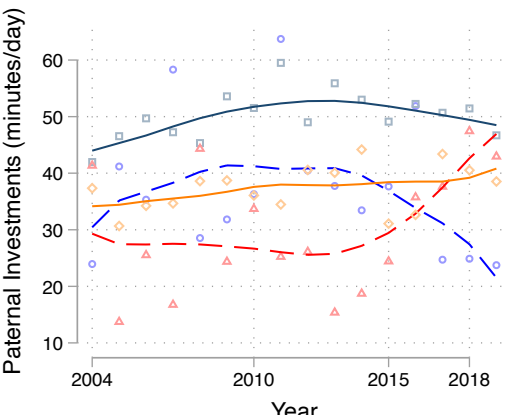

no BA, nonsummer

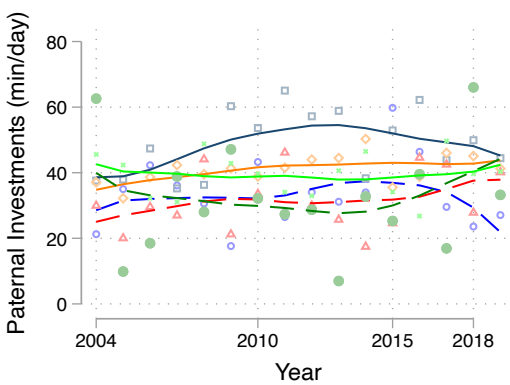

bottom quartile, summer

bottom quartile, nonsummer

Figure 2: Lowess Plots of Parental Investments over Time

Table 2 shows regression results more rigorously testing Hypotheses 3 and 4 . Model 1 examines the change over time in summer parental investments of money, with the focus on the SES $\times$ year interaction terms. Consistent with Figure 2, coefficients are larger for higher SES categories, but they are fairly small is magnitude and not statistically significant. In Model 2 we include non-summer observations and focus on the triple interaction of SES $\times$ summer $\times$ year. As above, these coefficients are not statistically significant. 
Table 2: Regression Models of Parental Investments over Time

\begin{tabular}{|c|c|c|c|c|c|c|}
\hline & \multicolumn{2}{|c|}{ Expenditures } & \multicolumn{2}{|c|}{ Maternal Time } & \multicolumn{2}{|c|}{ Paternal Time } \\
\hline & $\begin{array}{c}(1) \\
\text { Summer }\end{array}$ & $\begin{array}{c}(2) \\
\text { Full Year }\end{array}$ & $\begin{array}{c}(3) \\
\text { Summer }\end{array}$ & $\begin{array}{c}(4) \\
\text { Full Year }\end{array}$ & $\begin{array}{c}(5) \\
\text { Summer }\end{array}$ & $\begin{array}{c}\text { (6) } \\
\text { Full Year }\end{array}$ \\
\hline BA or higher & $\begin{array}{l}93.5^{* * *} \\
(14.2)\end{array}$ & $\begin{array}{l}77.6^{* * *} \\
(7.33)\end{array}$ & $\begin{array}{l}20.6^{*} \\
(9.56)\end{array}$ & $\begin{array}{l}23.9^{* * *} \\
(4.68)\end{array}$ & $\begin{array}{l}26.2^{* * *} \\
(7.33)\end{array}$ & $\begin{array}{l}15.7^{* * *} \\
(3.64)\end{array}$ \\
\hline Bottom income quartile & $\begin{array}{c}5.47 \\
(9.67)\end{array}$ & $\begin{array}{c}-13.3^{*} \\
(5.88)\end{array}$ & $\begin{array}{r}-12.1 \\
(9.11)\end{array}$ & $\begin{array}{c}7.71 \\
(4.53)\end{array}$ & $\begin{array}{c}1.00 \\
(8.49)\end{array}$ & $\begin{array}{r}0.057 \\
(4.47)\end{array}$ \\
\hline Top income quartile & $\begin{array}{l}90.6^{* * *} \\
(16.3)\end{array}$ & $\begin{array}{l}59.5^{* * *} \\
(7.19)\end{array}$ & $\begin{array}{r}6.99 \\
(10.8)\end{array}$ & $\begin{array}{l}11.4^{*} \\
(4.70)\end{array}$ & $\begin{array}{c}-4.36 \\
(7.86)\end{array}$ & $\begin{array}{c}0.46 \\
(3.79)\end{array}$ \\
\hline Summer & & $\begin{array}{c}-21.1^{* * *} \\
(4.88)\end{array}$ & & $\begin{array}{c}-7.32 \\
(4.97)\end{array}$ & & $\begin{array}{r}-13.5^{*} \\
(5.37)\end{array}$ \\
\hline Year & $\begin{array}{c}-0.025 \\
(0.45)\end{array}$ & $\begin{array}{c}-0.91^{* *} \\
(0.30)\end{array}$ & $\begin{array}{r}-1.04^{*} \\
(0.53)\end{array}$ & $\begin{array}{l}1.10^{* *} \\
(0.39)\end{array}$ & $\begin{array}{c}1.04 \\
(0.56)\end{array}$ & $\begin{array}{r}0.57^{*} \\
(0.27)\end{array}$ \\
\hline BA or higher $\times$ Year & $\begin{array}{c}0.56 \\
(1.33)\end{array}$ & $\begin{array}{c}-0.45 \\
(0.74)\end{array}$ & $\begin{array}{c}-0.11 \\
(1.01)\end{array}$ & $\begin{array}{l}-1.61^{* * *} \\
(0.48)\end{array}$ & $\begin{array}{r}-1.71^{*} \\
(0.72)\end{array}$ & $\begin{array}{c}-0.38 \\
(0.42)\end{array}$ \\
\hline Bottom income quartile $\times$ Year & $\begin{array}{c}-1.65 \\
(0.97)\end{array}$ & $\begin{array}{c}-0.041 \\
(0.73)\end{array}$ & $\begin{array}{l}1.10 \\
(1.01)\end{array}$ & $\begin{array}{r}-1.08^{*} \\
(0.51)\end{array}$ & $\begin{array}{c}-0.31 \\
(0.89)\end{array}$ & $\begin{array}{c}-0.44 \\
(0.54)\end{array}$ \\
\hline Top income quartile $\times$ Year & $\begin{array}{c}1.41 \\
(1.56)\end{array}$ & $\begin{array}{l}2.48^{* * *} \\
(0.70)\end{array}$ & $\begin{array}{c}-0.92 \\
(1.07)\end{array}$ & $\begin{array}{c}-0.69 \\
(0.51)\end{array}$ & $\begin{array}{c}0.26 \\
(0.80)\end{array}$ & $\begin{array}{c}0.29 \\
(0.43)\end{array}$ \\
\hline BA or higher $\times$ Summer & & $\begin{array}{l}16.7 \\
(14.2)\end{array}$ & & $\begin{array}{l}-3.85 \\
(10.5)\end{array}$ & & $\begin{array}{c}9.38 \\
(7.87)\end{array}$ \\
\hline Bottom income quartile $\times$ Summer & & $\begin{array}{c}20.0 \\
(10.4)\end{array}$ & & $\begin{array}{r}-19.3^{*} \\
(9.76)\end{array}$ & & $\begin{array}{c}0.093 \\
(9.40)\end{array}$ \\
\hline Top income quartile $\times$ Summer & & $\begin{array}{r}30.8^{*} \\
(15.2)\end{array}$ & & $\begin{array}{l}-4.98 \\
(11.6)\end{array}$ & & $\begin{array}{c}-5.04 \\
(8.87)\end{array}$ \\
\hline Summer $\times$ Year & & $\begin{array}{c}0.88 \\
(0.46)\end{array}$ & & $\begin{array}{l}-2.16^{* * *} \\
(0.58)\end{array}$ & & $\begin{array}{c}0.42 \\
(0.64)\end{array}$ \\
\hline BA or higher $\times$ Summer $\times$ Year & & $\begin{array}{c}1.02 \\
(1.37)\end{array}$ & & $\begin{array}{c}1.51 \\
(1.09)\end{array}$ & & $\begin{array}{c}-1.31 \\
(0.82)\end{array}$ \\
\hline Bottom income quartile $\times$ Summer $\times$ Year & & $\begin{array}{c}-1.46 \\
(1.05)\end{array}$ & & $\begin{array}{r}2.14^{*} \\
(1.09)\end{array}$ & & $\begin{array}{c}0.19 \\
(1.02)\end{array}$ \\
\hline Top income quartile $\times$ Summer $\times$ Year & & $\begin{array}{c}-1.05 \\
(1.47)\end{array}$ & & $\begin{array}{c}-0.18 \\
(1.23)\end{array}$ & & $\begin{array}{r}-0.075 \\
(0.94)\end{array}$ \\
\hline Observations & 54888 & 274445 & 3290 & 16687 & 2216 & 11534 \\
\hline
\end{tabular}

Standard errors in parentheses

${ }^{*} p<.05,{ }^{* *} p<.01,{ }^{* * *} p<.001$

Source: Consumer Expenditure Survey 1996-2018, American Time Use Survey 2003-2019. Controls included in all models. 
We next examine how parental investments of time in children during the summer and school year have changed over time. The remaining panels of Figure 2 show lowess plots charting maternal and parental childcare time from 2003-2019. We see some evidence of convergence in maternal SES gaps in school-year childcare time in recent years, with high-income and highly-educated mothers reducing their school-year childcare time and middle-income and less-educated mothers increasing this childcare time. However, we see that education-based gaps in maternal childcare remain wide during the summer, and appear to have widened in recent years. Conversely, for fathers, SES gaps in childcare during the school year have remained fairly constant over time, while SES gaps in the summer appear to have reversed somewhat in recent years.

In Model 3 of Table 2, we find no evidence that maternal SES gaps in summer childcare time have significantly widened between 2003 and 2019. However, the positive and significant Bottom income quartile $\times$ Summer $\times$ Year coefficient in Model 4 suggests that, in comparison to middle- and high-income mothers, low-income mothers decreased their childcare time in the summer by about two minutes less per year.

In Model 5 we find that more educated fathers have decreased their summer childcare time by about almost two minutes per year relative to other fathers between 2003 and 2019, consistent with the figure above showing a recent reversal in SES gaps in paternal time use by education. There is no significant difference between summer and school months in how these SES gaps in paternal childcare time have changed (Model 6).

Taken together, neither the most flexible visualization of the over-time trends in lowess plots of Figure 2 nor the linear models of Table 2 provide consistent evidence of a change over time in summer gaps in parental investments of money or time.

\subsection{Differences by Age}

Our final set of analyses examine whether summertime SES gaps in parental investments in children vary by the age of children. Model 1 of Table 3 presents the regression results predicting parental expenditures of money. Looking at the BA or higher $\times$ older coefficient, we find no significant difference by age of child for more and less educated families during the summer. However, we do find that families in the top income quartile spend about $\$ 55$ less $(\mathrm{p}<.05)$ on older children than younger children, compared to those in the middle income quartile.

To interpret the differences we plot the predicted summer expenditures by SES and age of child in the first column of Figure 3. We see that — as already shown in the analyses of Hypothesis 1-more-educated and higher-income families already spend more on children regardless of age. In addition, across every SES category families are predicted to spend more on younger children. However, high-income families in the top income quartiles spend especially more on young children ( $\$ 250$ month). Thus, these results provide some evidence in support of Hypothesis 5A. 
Table 3: Regression Models of Parental Investments by Age of Child

\begin{tabular}{|c|c|c|c|}
\hline & $\begin{array}{c}(1) \\
\text { Expenditures }\end{array}$ & $\begin{array}{c}(2) \\
\text { Maternal Time }\end{array}$ & $\begin{array}{c}(3) \\
\text { Paternal Time }\end{array}$ \\
\hline BA or higher & $\begin{array}{l}97.9^{* * *} \\
(11.0)\end{array}$ & $\begin{array}{l}14.1 \\
(8.75)\end{array}$ & $\begin{array}{l}18.2^{*} \\
(8.27)\end{array}$ \\
\hline Bottom income quartile & $\begin{array}{r}-18.5^{*} \\
(9.12)\end{array}$ & $\begin{array}{r}-5.41 \\
(8.27)\end{array}$ & $\begin{array}{c}2.77 \\
(7.59)\end{array}$ \\
\hline Top income quartile & $\begin{array}{l}144.8^{* * *} \\
(16.6)\end{array}$ & $\begin{array}{c}12.8 \\
(12.6)\end{array}$ & $\begin{array}{c}9.82 \\
(8.80)\end{array}$ \\
\hline Children ages $12-17$ & $\begin{array}{c}-43.6^{* * *} \\
(6.86)\end{array}$ & $\begin{array}{c}0.88 \\
(9.27)\end{array}$ & $\begin{array}{l}19.6^{*} \\
(9.51)\end{array}$ \\
\hline BA or higher $\times$ Children ages $12-17$ & $\begin{array}{c}12.7 \\
(17.1)\end{array}$ & $\begin{array}{c}2.78 \\
(9.45)\end{array}$ & $\begin{array}{r}-21.7^{*} \\
(9.26)\end{array}$ \\
\hline Bottom income quartile $\times$ Children ages $12-17$ & $\begin{array}{r}6.95 \\
(12.0)\end{array}$ & $\begin{array}{r}3.94 \\
(10.1)\end{array}$ & $\begin{array}{r}-9.56 \\
(9.27)\end{array}$ \\
\hline Top income quartile $\times$ Children ages $12-17$ & $\begin{array}{r}-54.5^{*} \\
(21.7)\end{array}$ & $\begin{array}{r}-22.3 \\
(13.5)\end{array}$ & $\begin{array}{r}-15.8 \\
(9.37)\end{array}$ \\
\hline Observations & 40923 & 2440 & 1653 \\
\hline
\end{tabular}

Standard errors in parentheses

${ }^{*} p<.05,{ }^{* *} p<.01,{ }^{* * *} p<.001$

Source: Consumer Expenditure Survey 1996-2018, American Time Use Survey 2003-2019. Controls and year fixed effects included in all models. Reference category for children's ages is children ages 6-11.

Models 2 and 3 of Tables 3 display the results of regression models testing whether SES gaps in maternal and paternal (respectively) investments of child care time during the summer differ between households with younger and older children. We see some evidence suggesting that SES gaps in maternal childcare time vary by the age of household children. The Top income quartile $\times$ Children ages 12-17 coefficient is negative and large in magnitude, though not statistically significant $(\mathrm{p}=.10)$. There is more evidence for fathers, as those with at least a BA spend about 22 fewer minutes with older children than younger children $(\mathrm{p}<.05)$ and those in the top income quartile spend 16 fewer minutes with older children than younger children $(\mathrm{p}=.09)$

Columns 2 and 3 of Figure 3 shows the SES gaps in childcare time during the summer by the age of household children. Notably, for fathers, while there are apparent education- and income-based gaps in summer childcare time among fathers with household children aged 6-11, these gaps are no longer apparent among fathers with household children aged 12-17.

In sum, we generally find evidence for Hypothesis 5A. Gaps by parental income in summer parental investments of money and by fathers education in paternal time use are wider among parents of younger children than older children, while gaps in family income for maternal and paternal time use are in the same direction and of a substantial magnitude, though not statistically significant. None of the results suggest support for Hypotheses 5B of a gap in the reverse direction. 

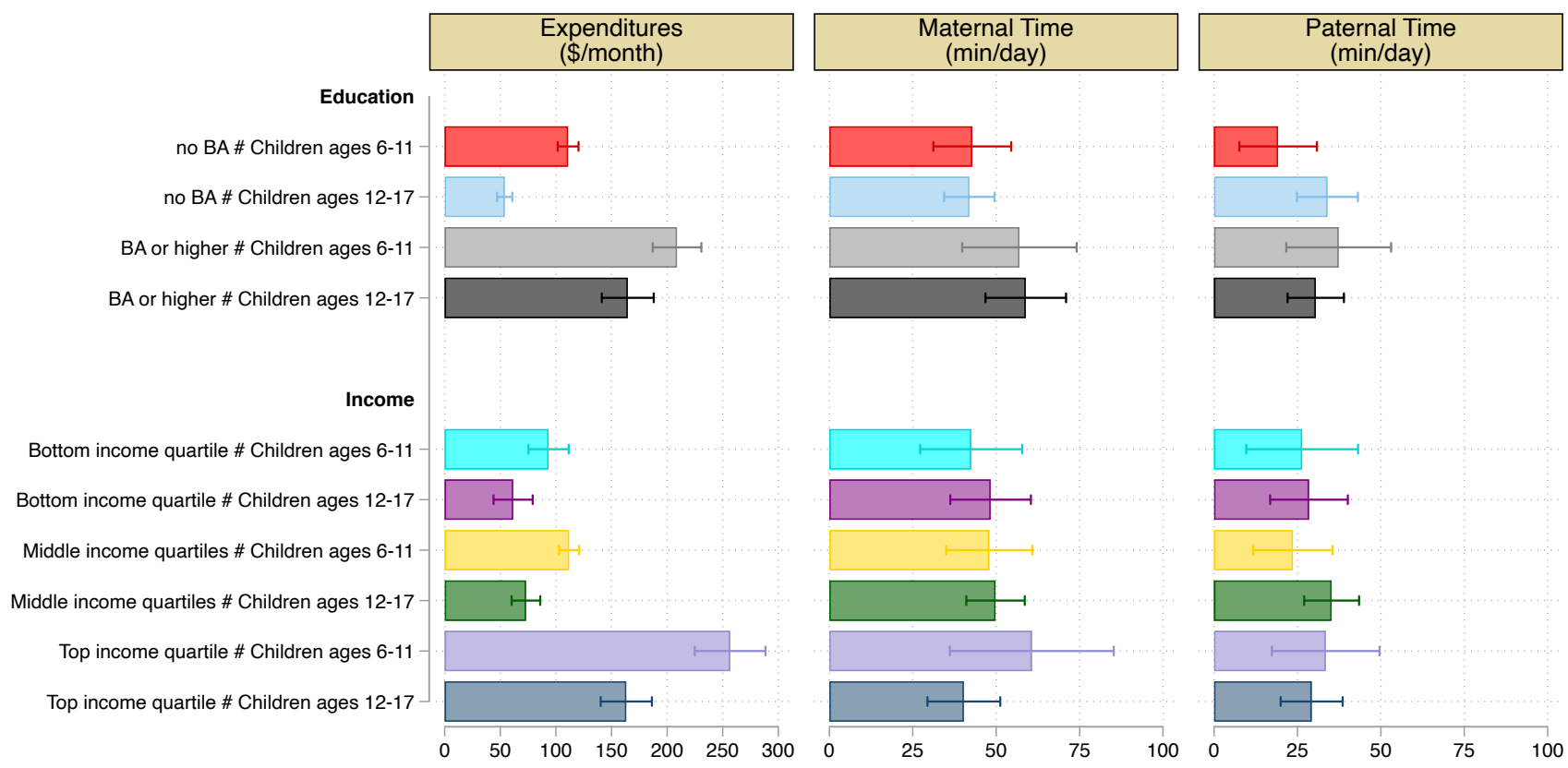

Figure 3: Predicted Parental Investments by Age of Child

\subsection{Robustness and Alternate Models}

We estimate several alternate models. First, we re-estimated all models using our SES indicators of education and income separately and provide these model results in the Appendix. Both income and education are distinct dimensions of SES, and scholars have extensively examined how both are important drivers of inequality in parental investment in children (Cheadle and Amato 2011; Hao and Yeung 2015). However, these measures are also strongly correlated. In general, these supplementary models of parental investments show similar or slightly larger SES differences than in our main models. For example, the conditional gap in parental expenditures for parents with a Bachelors degree compared to those without is $\$ 134 /$ month (vs $\$ 102$ ). The models of parental investments of time show substantively similar results to those that examine income and education combined.

Second, we considered the possibility that the high cost of public school spending could be driving the SES differences in parental investments of money. We do not know in our data what kind of school students attend, but in the U.S. roughly $10 \%$ of students attend private school (Murnane and Reardon 2018). As a proxy for private school attendance, we removed households in the top $10 \%$ of total spending on schooling and re-estimated our expenditure models. The results from these models (included in the Appendix) show that SES gaps in parental expenditures on children are reduced to approximately a third of their original size, but remain statistically significant. Thus, the finding of large SES gaps in parental expenditures is likely not driven exclusively by high-income parents paying for private schools, even though these parents are likely to disproportionately invest money in their children in childcare and enrichment activities as well.

Third, and relatedly, we estimated the expenditure models separately for expenditures on paid childcare and on everything but childcare (included in the Appendix). In both sets of models, we observe SES summer gaps, but they are larger for the non-childcare 
expenditures. In the models examining whether gaps are larger in the summer, we see the coefficients for both outcomes are in the same direction (i.e., widening gaps by parental income and education) but not necessarily statistically significant. In short, paid childcare contributes to SES summer gaps, but the findings are robust to excluding them. As in the main models, there is no distinct change over time in these gaps. Finally, in the models by children's age, we see the paid childcare gap is more substantial for parents of young families, while the remaining gaps exist among parents of older and younger children. This is not too surprising given that younger children are more in need of childcare, but - given that our time-use analysis found lower SES parents do not spend greater time doing childcare themselves in the summer - this raises questions about whether the differences for families of young children is lower SES parents paying less for childcare or finding more alternative arrangements such as extended family (exploring these questions would require different data).

\section{Discussion and Conclusion}

In this paper, we first examine whether or not higher-SES families invest more money and time in their children during the summer than lower-SES families; then, we examine whether or not these (expected) gaps in parental investments are larger in the summer than during the school year. We find gaps by parental education for both parental investments of both time and money during the summer, and we find large gaps by parental income for expenditures on children. These gaps for expenditures (but not time use) are larger in the summer than during non-summer months (including in models with household fixed effects). When considering both forms of investment together, the net result is greater SES gaps in parental investments during summer. As parental investments are presumably key source of summer learning (or lack thereof), this informs ongoing research surrounding the summer learning gap (Entwisle and 1995; Burkam et al. 2004; Downey et al. 2004; Alexander, Entwisle, and Olson 2007; von Hippel et al. 2018; von Hippel and Hamrock 2019). Further, these parental investments during the summer can help children develop other skills and cultural capital that may provide long-lasting benefits later in life (Rivera 2012; Turco 2010).

Next, we examine the over-time dimensions of the seasonality of SES gaps in parental investments in children. We hypothesized there would be a widening of summer SES gaps in parental investments in children over time, reflecting the rise of intensive parenting practices associated with concerted cultivation. However, we do not find significant evidence that they grew more in the summer over the period of our analysis or that they have widened more over time relative to during the school year. This suggests summer has not been a key source of increases in intensive parenting in the last two decades, though it is possible that summer SES gaps in parental investment grew during the 1980s and 1990s (Kornrich and Furstenberg 2013; Kornrich 2016; Altintas 2016; Schneider et al. 2018).

Finally, we examined differences in summer parental investments by children's ages. We find high-SES parents disproportionately increase their summer spending on younger school-aged children compared to older school-aged children. Though much of the narrative around concerted cultivation has focused on higher-SES parents investing in activities for older children to help them get into an elite college, some research suggests investments targeted at younger children have greater returns (Heckman 2006; Chetty, Hendren, and Katz 2016), and thus larger SES gaps in parental investments at this earlier stage seem more likely to be consequential for long-term inequalities in children's outcomes. 
This work is subject to some other important limitations which could be addressed in future research. We focus on aggregated measures of expenditures and time use. However, additional research could explore how these vary by different types of expenditures and child care time. For example the sub-categories of time use on teaching and management likely most closely capture the intensive parenting practices at the heart of concerted cultivation.

An additional limitation of the expenditure analysis (but not the time use analysis) already noted is that the data record the month of the expense. However, as discussed in the Data section, we would expect this to downwardly bias the differences between seasons (specifically affecting the tests of Hypotheses 2 and 4 for the expenditure analysis). Thus, our estimates of seasonal differences are likely conservative, and it is quite possible that class gaps in the investments purchased by parents that children actually experience during the summer are wider than our models actually report.

Finally, work is needed to understand how public expenditures in summer (e.g., summer school; day camps; recreation leagues) might directly affect private investments in children. To the extent that high-SES parents respond to decreases in public investments during the summer by "turning up" their private investments in their children, this may imply that increases in public investments in children during the summer may lead high-SES parents to "turn down" their investments in children. This has important policy implications, as it would reduce inequality in the total amount of resources that children receive and potentially help to narrow the summer learning gap.

Our work provides the first analysis that considers the seasonality of parental investments that includes both time and money. Considering these together is important because investments of time and money can involve tradeoffs, and, empirically, we find some notable differences in our results between the models of expenditures and time use. Taking both into account more fully reveals the extent of inequality in parental investments by SES. This research sheds new light on these important inequalities that can have long-term consequences on children's outcomes and post-secondary attainment. 


\section{References}

Alexander, Karl L., Doris R. Entwisle, and Linda Steffel Olson. 2007. "Lasting Consequences of the Summer Learning Gap." American Sociological Review 72(2):167-80.

Aikens, N. L., and O. Barbarin. 2008. "Socioeconomic differences in reading trajectories: The contribution of family, neighborhood, and school contexts." Journal of Educational Psychology 100:235-251. doi:10.1037/0022-0663.100.2.235

Altintas, Evrim. 2016. "The Widening Education Gap in Developmental Child Care Activities in the United States, 1965-2013." Journal of Marriage and Family 78(1):2642 .

Auwarter, Amy E. and Mara S. Aruguete. 2008. "Effects of Student Gender and Socioeconomic Status on Teacher Perceptions" The Journal of Educational Research 101(4):242-246. doi:10.3200/JOER.101.4.243-246

Bassok, Daphna, Jenna E. Finch, RaeHyuck Lee, Sean F. Reardon, and Jane Waldfogel. 2016. "Socioeconomic Gaps in Early Childhood Experiences: 1998 to 2010" AERA Open 2(3):1-22. doi:10.1177/2332858416653924

Bassok, Daphna, Scott Latham, and Anna Rorem. 2016. "Is Kindergarten the New First Grade?" AERA Open 1(4):1-31. doi:10.1177/2332858415616358

Bennett, Pamela R., Amy C. Lutz, and Lakshmi Jayaram. 2012. "Beyond the schoolyard: The role of parenting logics, financial resources, and social institutions in the social class gap in structured activity participation." Sociology of Education 85(2):131-157.

Bianchi, Suzanne M. 2000. "Maternal employment and time with children: Dramatic change or surprising continuity?" Demography 37:401-414.

Bianchi, Suzanne, John Robinson, and Melissa Milkie. 2006. The Changing Rhythms of American Family Life. New York: Russell Sage.

Blau, Peter M. and Otis Dudley Duncan. 1967. The American Occupational Structure. New York: Wiley.

Bloome, Dierdre, Shauna Dyer, and Xiang Zhou. 2018. "Educational Inequality, Educational Expansion, and Intergenerational Income Persistence in the United States." American Sociological Review 83(6):1215-1253.

Bodovski, Katerina and George Farkas. 2008. " 'Concerted Cultivation' and Unequal Achievement in Elementary School." Social Science Research 37(3):903-919.

Burkam, David T., Douglas D. Ready, Valerie E. Lee, and Laura F. LoGerfo. 2004. "SocialClass Differences in Summer Learning Between Kindergarten and First Grade: Model Specification and Estimation." Sociology of Education 77(1):1-31.

Calarco, Jessica McCrory. 2018. Negotiating Opportunities: How the Middle Class Secures Advantages in School. New York: Oxford University Press.

Cascio, Elizabeth and Diane Whitmore Schanzenbach. 2013. "The Impacts of Expanding Access to High-Quality Preschool Education." Brookings Papers on Economic Activity $47(2): 127-192$. 
Cha, Yun and Hyunjoon Park. 2020. "Converging Educational Differences in Parents' Time Use in Developmental Child Care." Journal of Marriage and Family 83(3):769-785.

Cheadle, Jacob. 2009. "Parent Educational Investment and Children's General Knowledge Development." Social Science Research 38:477-491.

Cheadle, Jacob. 2008. "Educational Investment, Family Context, and Children's Math and Reading Growth from Kindergarten Through the Third Grade." Sociology of Education 81:1-31.

Cheadle, Jacob E. and Paul R. Amato. 2011. "Concerted Cultivation: A Quantitative Assessment of Lareau's Conclusions about Social Class, Race, and Parenting Practices." Journal of Family Issues 32:679-706. doi:10.1177/0192513X10386305

Chetty, Raj, David Grusky, Maximilian Hell, Nathaniel Hendren, Robert Manduca, and Jimmy Narang. 2017. "The Fading American Dream: Trends in Absolute Income Mobility Since 1940." Science.

Chetty, Raj, Nathaniel Hendren, and Lawrence F. Katz. 2016. "The Effects of Exposure to Better Neighborhoods on Children: New Evidence from the Moving to Opportunity Experiment." American Economic Review 106(4):855-902.

Chetty, Raj, Nathaniel Hendren, Patrick Kline, Emmanuel Saez, and Nick Turner. 2014. "Is the United States Still a Land of Opportunity? Recent Trends in Intergenerational Mobility" American Economic Review Papers and Proceedings 104(5):141-147.

Chin, Tiffani and Meredith Phillips. 2004. "Social Reproduction and Childrearing Practices: Social Class, Children's Agency, and the Summer Activity Gap." Sociology of Education $77: 185-210$.

Cooper, Marianne. 2014. Cut Adrift: Families in Insecure Times. Berkeley: University of California Press.

Corak, Miles. 2013. "Income Inequality, Equality of Opportunity, and Intergenerational Mobility" Journal of Economic Perspectives 27(3):79-102.

Crosnoe, Robert. 2009. "Low-Income Students and the Socioeconomic Composition of Public High Schools" American Sociological Review 74(5):709-730. doi: $10.1177 / 000312240907400502$

Duncan, Greg and Richard Murnane. 2011. "Introduction: The American Dream, Then and Now." In Whither Opportunity: Rising Inequality, Schools, and Children's Life Chances. Eds. Murnane and Duncan. New York: Russell Sage Foundation Press.

Downey, Douglas B., Paul T. von Hippel, and Beckett A. Broh. 2004. "Are Schools the Great Equalizer? Cognitive Inequality during the Summer Months and the School Year." American Sociological Review 69(5):613-35.

Education Finance Statistics Center (EDFIN). 2012. "School district current expenditures per pupil with and without adjustments for federal revenues by poverty and race/ethnicity characteristics." Table A-1. 
Entwisle, Doris R., and Karl L. Alexander. 1995. "A Parent's Economic Shadow: Family Structure Versus Family Resources as Influences on Early School Achievement." Journal of Marriage and Family 57(2):399-409.

Entwisle, Doris R., Karl L. Alexander, and Linda Steffel Olson. 2001. "Keep the Faucet Flowing." American Educator 25(3):10-15.

Gamoran, Adam. 1992. "The Variable Effects of High School Tracking." American Sociological Review 57(6):812-828.

Gauthier, Anne H., Timothy M. Smeeding, and Frank F. Furstenberg Jr. 2004 "Are Parents Investing Less Time in Children? Trends in Selected Industrialized Countries." Population Development and Review 30(4):647-672.

Gershenson, Seth. 2013. "Do Summer Time-Use Gaps Vary by Socioeconomic Status?" American Educational Research Journal 50(6):1219-48.

Goldstein, Adam and Orestes P. Hastings. 2019. "Buying In: Positional Competition, Schools, Income Inequality, and Housing Consumption." Sociological Science 6:416-445.

Greeman, Emily, Katerina Bodovski, and Katherine Reed. 2011. "Neighborhood Characteristics, Parental Practices and Children's Math Achievement in Elementary School." Social Science Research 40(5):1434-1444.

Hao, Lingxin and Wei-Jun Jean Yeung. 2015. "Parental Spending on School-Age Children: Structural Stratification and Parental Expectation." Demography 52(3):835-860.

Hastings, Orestes P. and Daniel Schneider. 2021 "Family Structure and Inequalities in Parents' Financial Investments in Children." Journal of Marriage and Family 83(3):717736.

Heckman, James J. 2006. "Skill Formation and the Economics of Investing in Disadvantaged Children." Science 312(5782):1900-1902.

Heckman, James J. 2008. "Schools, Skills, and Synapses." Economic Inquiry 46(3):289-324.

Hill, Rachelle, Sarah Flood, and Katie Genadek. 2018. "Weekend and Weekdays in Time Diary Analysis." Presentation at the 2018 PAA Annual Meeting.

Hsin, Amy and Christina Felfe. 2014. "When Does Time Matter? Maternal Employment, Children's Time With Parents, and Child Development." Demography 51(5):1867-1894.

von Hippel, Paul T. and Caitlin Hamrock. 2019. "Do Test Score Gaps Grow before, during, or between the School Years? Measurement Artifacts and What We Can Know in Spite of Them." Sociological Science 6:43-80.

von Hippel, Paul T., Joseph Workman, and Douglas B. Downey. 2018. "Inequality in Reading and Math Skills Forms Mainly before Kindergarten: A Replication, and Partial Correction, of 'Are Schools the Great Equalizer?"' Sociology of Education 91(4):323-57.

Hofferth, Sandra L., Sarah M. Flood and Matthew Sobek. American Time Use Survey Data Extract Builder: Version 2.7 [dataset]. College Park, MD: University of Maryland and Minneapolis, MN: IPUMS, 2018. doi:10.18128/D060.V2.7 
Hout, Michael. 2018. "Americans' occupational status reflects the status of both of their parents" PNAS 115(38):9527-9532.

Ishizuka, Patrick. 2019. "Social Class, Gender, and Contemporary Parenting Standards in the United States: Evidence from a National Survey Experiment." Social Forces $98(1): 31-58$.

Jackson, Margot, and Daniel Schneider. 2021. "Public Investments and Class Gaps in Parents' Developmental Expenditures." (EdWorkingPaper: 21-376). Retrieved from the Annenberg Institute at Brown University. doi:doi.org/10.26300/m5r4-1t20

Kalil, Ariel, Rebecca Ryan, and Michael Corey. 2012. "Diverging Destinies: Maternal Education and the Developmental Gradient in Time With Children." Demography 49:1361-1383.

Kalil, Ariel, Kathleen M. Ziol-Guest, Rebecca M. Ryan, and Anna J. Markowitz. 2016. "Changes in Income-Based Gaps in Parent Activities With Young Children from 1988 to 2012." AERA Open 2(3):1-17.

Kornrich, Sabino. 2016. "Inequalities in Parental Spending on Young Children: 1972 to 2010." AERA Open 2(2):1-12.

Kornrich, Sabino and Frank Furstenberg. 2013. "Investing in Children: Changes in Parental Spending on Children, 1972-2007." Demography 50(1):1-23.

LaBriola, Joe and Daniel Schneider. 2021. "Class Inequality in Parental Childcare Time: Evidence from Synthetic Couples in the ATUS." Social Forces. Online first. doi:10.1093/sf/soaa13

Lareau, Annette. 2002. "Invisible Inequality: Social Class and Childrearing in Black Families and White Families." American Sociological Review 67(5):747-76.

Lareau, Annette. 2011. Unequal Childhoods: Class, Race, and Family Life. University of California Press.

Meyer, D., Princiotta, D., and Lanahan, L. 2004. "The Summer After Kindergarten: Children's Activities and Library Use by Household Socioeconomic Status" NCES 2004037. U.S. Department of Education. Washington, DC: National Center for Education Statistics.

Mitnik, Pablo A., Victoria Bryant, and David Grusky. 2018. "A Very Uneven Playing Field: Economic Mobility in the United States" Stanford Center on Poverty and Inequality.

Mitnik, Pablo A., Victoria Bryant, and Michael Weber. 2019. "The Intergenerational Transmission of Family-Income Advantages in the United States" Sociological Science. doi:10.15195/v6.a15

Murnane, Richard J. and Sean F. Reardon. 2018. "Long-term trends in private school enrollments by family income" AERA Open 4(1). doi:10.1177/2332858417751355

Oakes, Jeannie. 2005. Keeping Track. Yale University Press.

Owens, Ann, Sean F. Reardon, and Christopher Jencks. 2016. "Income segregation between schools and school districts." American Educational Research Journal 53:1159-1197. 
Park, Hyunjoon, Claudia Buchmann, Jaesung Choi, and Joseph J. Merry. 2016. "Learning Beyond the School Walls: Trends and Implications." Annual Review of Sociology 42:231-252.

Pfeffer, Fabian T. and Alexandra Killewald. 2018. "Generations of Advantage. Multigenerational Correlations in Wealth" Social Forces 96(4): 1411-1442.

Price, Joseph and Ariel Kalil. 2018. "The Effect of Mother-Child Reading Time on Children's Reading Skills: Evidence from Natural Within-Family Variation." Child Development.

Prickett, Kate C., and Jennifer March Augustine. 2021. "Trends in Mothers' Parenting Time by Education and Work From 2003 to 2017." Demography 58(3):1065-1091.

Ramey, Garey and Valerie Ramey. 2010. "The Rug Rat Race." Brookings Papers on Economic Activity Spring: 129-176.

Reardon, Sean and Ximena Portilla. 2016. "Recent Trends in Income, Racial, and Ethnic School Readiness Gaps at Kindergarten Entry." AERA Open 2(3):1-18.

Redford, Jeremy, Stephanie Burns, and L. Jane Hall. 2018. "The Summer After Kindergarten: Children's Experiences by Socioeconomic Characteristics" NCES 2018-160. U.S. Department of Education. Washington, DC: National Center for Education Statistics.

Rivera, Lauren A. 2012. "Hiring as Cultural Matching: The Case of Elite Professional Service Firms." American Sociological Review 77(6):999-1022.

Sayer, Liana C., Anne H. Gauthier, and Frank F. Furstenberg Jr. 2004. "Educational differences in parents' time with children: Cross-national variations." Journal of Marriage and Family 66(5):1152-1169.

Schneider, Daniel, Orestes P. Hastings, and Joe LaBriola. 2018. "Income Inequality and Class Divides in Parental Investments." American Sociological Review 83(3):475-507.

Turco, Catherine. 2010. "The Cultural Foundations of Tokenism: Evidence from the Leveraged Buyout Industry." American Sociological Review 75(6):894-913. 